\title{
O uso de smartphones no ensino e na aprendizagem da língua inglesa: o que dizem os professores?
}

\author{
Daniele Alves Ribeiro ${ }^{\mathrm{i}}$ \\ Diogo Orlando Elias do Espírito Santo ${ }^{\mathrm{ii}}$ \\ Leonardo Jovelino Almeida de Lima ${ }^{\text {iii }}$
}

\section{RESUMO}

Este artigo tem como objetivo principal verificar e discutir a visão dos docentes quanto ao uso de smartphones em sala de aula. Assim, este trabalho está norteado pela pesquisa de cunho bibliográfico e baseado na análise qualitativa, e contou com o levantamento de artigos, monografias e dissertações de mestrado que objetivam trazer percepções e opiniões de docentes sobre o uso de smartphones em sala de aula. A partir de nossas análises e discussões, entendemos que, mesmo que haja o interesse no trabalho com smartphones em sala de aula por parte de muitos docentes, a questão da formação e da conscientização para os benefícios da aprendizagem móvel ainda parece ser uma questão necessária e de suma importância.

Palavras-chave: Smartphones; Ensino-aprendizagem; Professores.

\begin{abstract}
This article aims to verify and discuss the teachers' views regarding the use of smartphones in class. In this sense, this work is guided by bibliographic research and it is based on qualitative analysis. It relies on articles, monographs and master's dissertations that cover teachers' perceptions and opinions about the use of smartphones in the teaching-learning process. According to our analysis and discussions, we understand that, even though many teachers are interested in working with smartphones
\end{abstract}

\footnotetext{
i Possui graduação em Letras - Português/Inglês pela Universidade Federal do Rio de Janeiro (2011), especialização em Educação Especial Inclusiva pela AVM Faculdade Integrada (2015), e graduação em Turismo pela Universidade Federal do Estado do Rio de Janeiro (2007). Atualmente, é mestranda do Programa de Pós-Graduação em Letras da Universidade do Estado do Rio de Janeiro. ORCID: https://orcid.org/0000-0002-1822-266X | danielearibeiro@yahoo.com

ii Possui graduação em Letras - Inglês pela Universidade do Estado do Rio de Janeiro (2011). Atualmente é professor de inglês da Prefeitura da Cidade do Rio de Janeiro. Pós-graduado na área de Tradução. Atualmente, é mestrando do Programa de Pós-Graduação em Letras da Universidade do Estado do Rio de Janeiro.

E-mail: $\underline{\text { diogo.orlando1@gmail.com }}$

iii Possui graduação em Letras com Habilitação em Língua Inglesa pela Universidade Federal do Pará (2018) e Especialização em Literatura Inglesa pela Faculdade São Luis (2019). Atualmente, é mestrando do Programa de Pós-Graduação em Letras da Universidade do Estado do Rio de Janeiro. ORCID: https://orcid.org/0000-0001-9299-3182 | leolimamat@ hotmail.com
} 
in class, proper training and awareness of the benefits of mobile learning still seem to be necessary and important issues.

Keywords: Smartphones; Teaching-learning process; Teachers.

\section{INTRODUÇÃO}

É inegável que, hoje em dia, os smartphones são uma realidade no nosso cotidiano. As pessoas realizam inúmeras atividades, referentes a diversas esferas da vida, pelos smartphones. Uma pesquisa feita em 2018 pelo Instituto Brasileiro de Geografia e Estatística (IBGE), sobre o uso das Tecnologias de Informação e Comunicação (TICs) nos domicílios brasileiros, revelou que 79,1\% dos domicílios brasileiros tinha acesso à internet naquele ano. Em 99,2\% dos casos, o acesso era a partir de telefones celulares (IBGE, 2020). Percebe-se, portanto, que, já em 2018, os telefones celulares, em sua maioria smartphones, eram os dispositivos mais utilizados para se conectar à internet no Brasil.

No ambiente escolar, essa realidade não é diferente. Tanto os professores como os alunos, em sua maioria, possuem smartphones. Embora haja uma lei que proíba o uso de telefones celulares e aparelhos eletrônicos em sala de aula no Rio de Janeiro (Lei Municipal 4.734 de 04 de janeiro de 2008), por exemplo, o uso desses aparelhos pelos alunos - com jogos, redes sociais, aplicativos de mensagens, etc. - é frequente, causando dispersão da atenção e falta de interesse na aula, conforme percebemos frequentemente em nossas práticas. A atenção dos jovens parece estar sempre voltada para esses dispositivos móveis.

Em um mundo onde as pessoas estão cada vez mais conectadas e fazendo o uso de seus aparelhos eletrônicos o tempo todo, em todas as esferas sociais, será que uma lei como a 4.734 de 04 de janeiro de 2008 (que dispõe sobre a proibição do uso de celulares em sala de aula no município do Rio de Janeiro) não acaba por contribuir para afastar ainda mais o jovem da escola, diminuindo seu interesse? Dada esta realidade, será que não seria melhor, e mais produtivo, em vez de repelir essa tecnologia, que já está mesmo presente em sala de aula - ainda que de modo ilegal - incorporá-la para fins pedagógicos? 
Por outro lado, embora a Organização das Nações Unidas para a Educação, a Ciência e a Cultura (UNESCO) aponte vantagens no uso dos smartphones como ferramenta pedagógica em sala de aula (UNESCO, 2014), muitos professores ainda encaram esse uso como um problema ou um grande desafio. Há aqueles que são radicalmente contra os celulares, enquanto outros usam e recomendam o uso desses dispositivos móveis.

Como professores de língua inglesa atuantes no ensino básico, consideramos importante e benéfico o uso dos smartphones na aprendizagem da língua especificamente, mas acreditamos que esse benefício se estende também para as demais disciplinas componentes do currículo. Portanto, nosso objetivo no presente estudo é entender a visão dos professores do contexto público ou particular sobre esse uso, independente das disciplinas que lecionam. A opção por esse recorte se deve ao fato de que, guardadas as especificidades da cada disciplina, acreditamos que as possíveis vantagens e dificuldades percebidas pelos docentes não dependem das características das disciplinas, mas sim das características das instituições de ensino e da própria cultura escolar como um todo.

Dessa forma, este breve estudo tem como objetivo principal verificar e discutir a visão dos docentes quanto ao uso de smartphones em sala de aula. Para o atingimento desse objetivo apresentado, buscou-se responder às seguintes perguntas: os docentes utilizam tecnologias digitais em sala de aula? Quais são as tecnologias digitais mais frequentemente usadas? Na visão dos docentes, a instituição de ensino incentiva o uso de smartphones em sala de aula? E ainda, quais são as vantagens e os entraves, na visão desses profissionais, relacionados a esse uso em sala de aula?

Para encontrar respostas a essas perguntas, foi feita uma pesquisa bibliográfica apoiada em artigos, monografias e dissertações de mestrado que tratam da visão docente sobre o uso de smartphones para fins pedagógicos.

\section{REFERENCIAL TEÓRICO}

O número excessivo de usuários de celulares tem gerado uma série de discussões sobre os possíveis benefícios e malefícios que o aparelho proporciona no contexto educativo. De acordo com a UNESCO (2014), as tecnologias móveis, por serem 
altamente portáteis e relativamente baratas, ampliaram enormemente o potencial e a viabilidade da aprendizagem personalizada. Além disso, à medida que aumentam o volume e a diversidade de informações que os aparelhos móveis podem coletar sobre seus usuários, a tecnologia móvel torna-se capaz de melhor individualizar a aprendizagem. A instituição diz ainda que, além disso, os aparelhos móveis inteligentes — muitos deles já nos bolsos de milhões de pessoas — podem oferecer aos estudantes maior flexibilidade para avançar em seu próprio ritmo e seguir seus próprios interesses, aumentando potencialmente sua motivação para buscar oportunidades de aprendizagem. (UNESCO, 2014).

Debates acerca da implementação de atividades provindas de dispositivos móveis em sala de aula crescem ininterruptamente no Brasil. Tais discussões devem-se ao fato do brasileiro estar cada vez mais conectado à internet e apegado aos dispositivos móveis. Segundo a Empresa Brasil de Comunicação, em uma matéria publicada em janeiro de 2019, os brasileiros passaram mais de três horas por dia usando o celular em 2018. Tal média pôs o país em $5^{\circ}$ lugar no ranking global de tempo despendido com o aparelho em questão. O dado é do relatório Estado de Serviços Móveis, elaborado pela consultoria especializada em dados sobre aplicativos para dispositivos móveis App Annie, considerando um dos mais completos do mundo. E quando fazemos uma análise mais ampla, levando em consideração os diversos aparelhos tecnológicos, os números são ainda mais alarmantes. De acordo com os dados informados pela coluna Época Negócios, em uma matéria publicada em abril de 2019 no site globo.com, o Brasil tem, atualmente, dois dispositivos digitais por habitante, incluindo smartphones, computadores, notebooks e tablets. Houve uma estimativa de que, no ano de 2019, o país teria em torno de 420 milhões de aparelhos digitais ativos. Entre todos os aparelhos citados, o smartphone é indubitavelmente o mais popular: segundo o levantamento, há, hoje, 230 milhões de celulares ativos no País.

A utilização da tecnologia da informação no âmbito educacional tem crescido substancialmente durante a última década. Segundo Milrad (2007), os avanços no setor de telefonia e das tecnologias sem fio também têm trazido um impacto significativo no cenário educativo, gerando assim uma aprendizagem que preza pelo uso de recursos tecnológicos, chamada de m-learning (aprendizagem móvel). Tal definição baseia-se na 
premissa de que o dispositivo móvel pode servir como alicerce para o contexto pedagógico.

Santaella (2013) também aborda este conceito. Segundo a autora, m-learning também denominada como aprendizagem móvel, é aquela que conta com "ferramentas para a educação que podem fazer o aprendizado chegar a quaisquer lugares". Além disso, a autora afirma ainda que "a m-learning é vista como uma extensão da sala de aula e é executável a partir da geração de conteúdos previamente estabelecidos". (SANTAELLA, 2013, p. 25).

O desenvolvimento acelerado das tecnologias de última geração combinado com o acesso a conteúdos variados em qualquer hora e lugar, permitem que os aprendizes tenham novas experiências de aprendizado em um ambiente mais tecnológico com o suporte de aparelhos eletrônicos sem fio e que propiciam uma aprendizagem contínua (MILRAD, 2007). O autor ainda diz que todas essas possibilidades de usufruir de multimídias interativas em celulares no contexto escolar oferecem alternativas inovadoras que podem auxiliar os aspectos pedagógicos, colaborativos e comunicativos. Partindo da premissa de que a revolução da internet afeta a maneira pela qual as pessoas interagem, a verdadeira transformação deve ocorrer com a combinação entre os recursos e o uso educacional, a fim de proporcionar a inserção adequada dos dispositivos móveis na educação. (MILRAD, 2007).

Há certos fatores inerentes ao contexto escolar que podem ser aprimorados com a eventual inserção dos celulares em sala de aula. Alguns aplicativos disponíveis em lojas online podem servir de alicerce e complementação para os materiais didáticos oferecidos pelas escolas, pois grande parte do material em questão contém características e informações provenientes de países cuja língua nativa é o inglês. Portanto, um dos possíveis benefícios que a utilização dos dispositivos móveis pode proporcionar ao corpo discente é o intercâmbio cultural, devido às informações oriundas de várias partes do mundo que são disponibilizadas na rede virtual. (MELO e NEVES, 2014).

Dentre as principais potencialidades oferecidas pelos dispositivos móveis para o ensino-aprendizagem destacam-se a ampliação do acesso a conteúdos pedagógicos, a possibilidade de criação de comunidades de aprendizagem ativa, interativa e colaborativa. A participação em comunidades de aprendizagem proporciona 
intercâmbio multicultural; é a aposta nessa interconexão entre diferentes pessoas e culturas que pode potencializar a construção de conhecimento dentro e fora da sala aula. (MELO e NEVES, 2014, p. 2).

No que tange à aprendizagem de língua inglesa, os usuários são submetidos a uma intensa exposição de conteúdos em inglês encontrados em aplicativos, jogos e sites. Aqueles que usufruem destes recursos com frequência possivelmente apresentarão um conhecimento mais aprofundado tanto de valores culturais quanto de expressões e vocábulos usados com recorrência em inglês. A aplicação de tecnologias da informação possibilita a busca de conhecimento em outro idioma. No caso do Inglês, é importante considerar também que a língua é um instrumento de acesso à internet, uma vez que grande parte do vocabulário usual da informática emprega a língua inglesa, idioma que também é predominante nos sites da internet. (BRASIL, 2002, p. 100).

Além de todos os benefícios oriundos dos dispositivos móveis, como mensagens instantâneas, chamadas de vídeo, áudios de diversos formatos, internet, entre outros, os smartphones têm crescido exponencialmente como ferramenta para a educação e para o aprendizado de línguas, e tanto os professores quanto os alunos estão acostumando-se a este ambiente educativo mais tecnológico (MIANGAH e NEZARAT, 2012). Os autores ponderam sobre as vantagens mencionadas e afirmam que

[...] o surgimento da internet abriu a possibilidade para a aprendizagem à distância e acesso a conteúdos educativos de todas as partes do mundo. Em um curto período de tempo, a atratividade da aprendizagem à distância nos leva à percepção de que diversos dispositivos móveis acabam sendo recursos bem eficazes para o ensino e para o aprendizado. De fato, foi uma questão desafiadora elaborar atividades pedagógicas através do aparelho celular. (MIANGAH, T. M., \& NEZARAT, A. ,2012. p. 313, tradução nossa) ${ }^{1}$

Ainda segundo Miangah e Nezarat (2012), aplicativos que estimulam o aprendizado da língua inglesa permitem que o usuário tenha acesso a conteúdos digitais quando e onde desejar. Para os especialistas, o inglês é considerado um fator determinante para o sucesso profissional e, portanto, prover um ambiente escolar mais conveniente para as pessoas aprenderem inglês é uma das estratégias pedagógicas que visa melhorar os resultados dos estudantes e auxiliar as diferentes necessidades de aprendizagem. 
Uma das habilidades relacionadas à aquisição de uma língua estrangeira que podem ser desenvolvidas por recursos disponíveis em aparelhos móveis é a prática da leitura. Segundo Chen e Hsu (2008), as práticas de leitura auxiliam os aprendizes a adquirirem mais vocábulos e, conhecimentos de vocabulário, por sua vez, ajudam a promover compreensão de leitura. No que se refere ao mundo digital, a gama de aplicativos que oferecem leituras de textos em inglês e suas respectivas traduções é abrangente. Alguns desses apps oferecem apenas a leitura na língua selecionada, outros traduzem o texto por completo ou fornecem a opção de traduzir cada palavra ou expressão e alguns apresentam uma proposta de leitura mais dinâmica (com a inclusão de imagens em movimento e sons embutidos no processo da leitura). Se bem conduzidos, tais elementos podem colaborar com o desenvolvimento mais efetivo das práticas de leitura e aquisição de vocabulário na língua adicional.

Contudo, a aprendizagem móvel também enfrenta sérios desafios, pois os dispositivos móveis, principalmente os telefones celulares, são vistos por educadores e gestores como "prejudiciais" ou "como um fator de distração" em sala de aula, razão pela qual o uso de dispositivos móveis em sala de aula é proibido na maior parte das instituições educacionais brasileiras. (MELO e NEVES, 2014).

Apesar da tentativa de inúmeros profissionais da educação defenderem a legalidade do uso de celulares, apenas implementá-los em sala de aula não implicará em resultados no aspecto cognitivo do aprendiz. Fonseca (2013) considera irrefutável a capacidade de uma tecnologia multifuncional como o telefone celular. Entretanto, para o autor, apenas a inserção desta tecnologia em processos de ensino-aprendizagem não garante que o processo será eficaz e atual. Para que isto ocorra, alunos e professores precisam compreender que tais aparelhos eletrônicos apenas permearão a sala de aula para fins didáticos, através de atividades pedagógicas previamente elaboradas. $\mathrm{O}$ autor ainda defende que

\footnotetext{
Em se tratando de tecnologia, o potencial não reside nela própria, e sim na interação com o homem. Desse modo, é preciso que os envolvidos, neste caso, alunos e professores, estejam preparados e dispostos, para que essa apropriação possa de fato representar transformação e gerar ganhos para a Educação. É preciso lembrar que mesmo as tecnologias possuem limitações e não devem ser vistas como solução, um fim. No caso do Mobile Learning, a falta de bateria e banda larga suficiente pode comprometer o trabalho, fundamentais para a mobilidade, acesso e compartilhamento. (FONSECA, 2013, p.165).
} 
As dificuldades estruturais apontadas por Fonseca (2013) fazem parte da realidade de muitas escolas em território nacional. Muitas delas ainda não possuem internet de banda larga e, as que possuem, muitas vezes não a disponibilizam para os estudantes. $\mathrm{O}$ uso da internet em diversas escolas do país é restrito a funcionários, tais como professores, coordenadores e componentes da direção.

Sonego e Behar (2015) explicam que este tipo de aprendizagem com tecnologias móveis oportuniza possibilidades aos estudantes para construir e intensificar seu processo de ensino-aprendizagem em qualquer hora e local, e que a M-Learning pode ocorrer em ocasiões em que a aprendizagem oferece ao estudante meios para obter vantagem das tecnologias móveis. Entretanto, os autores dizem que não se pode afirmar que o simples fato de utilizar um smartphone para desempenhar uma atividade em aula pode caracterizar-se como M-Learning. Para eles, deve-se ter um planejamento que envolva um conteúdo curricular, material didático e uma atividade de estudo. (SONEGO e BEHAR, 2015).

Diante das dificuldades estruturais encontradas no ensino como um todo, talvez seja necessário repensar os modelos das instituições educacionais. A fim de que ocorra aprendizagem de língua estrangeira por intermédio dos dispositivos móveis, as escolas poderiam elaborar estratégias em conjunto com a comunidade escolar para que o ensino fosse mais eficaz e produtivo.

\section{METODOLOGIA}

$\mathrm{Na}$ intenção de responder as perguntas estipuladas na introdução, este trabalho está norteado pela pesquisa de cunho bibliográfico e baseado na análise qualitativa. As pesquisas bibliográficas exigem uma articulação de ideias e observações oferecidas por outros pesquisadores para que ocorra não somente a consolidação de um estudo descritivo, mas, principalmente, o alcance analítico de questões. (LIMA, 2004). Compreendemos, portanto, que as pesquisas bibliográficas oferecem uma nova visão, um novo enfoque, sobre determinado tema, favorecendo, com isso, o atingimento de conclusões inovadoras. (MARCONI e LAKATOS, 1999). 
Desse modo, realizamos o levantamento de artigos, monografias e dissertações de mestrado que objetivam trazer percepções e opiniões de docentes sobre o uso de smartphones em sala de aula. Esse levantamento contou com os seguintes momentos:

1) Acesso à plataforma Google Acadêmico (Google Scholar) ${ }^{2}$ e filtragem de pesquisas usando as palavras-chave 'smartphones', 'docentes', 'ensino', 'línguas'; realizadas nos últimos cinco anos;

2) Através da leitura dos resumos, das introduções e das considerações finais, selecionamos as vinte primeiras pesquisas que, possivelmente, pudessem responder às perguntas estipuladas para este trabalho;

3) Finalmente, efetuamos uma leitura mais detalhada das pesquisas selecionadas com o intuito de identificar opiniões e percepções de docentes sobre o uso do smartphones no processo de ensino-aprendizagem. Assim, como material para a análise qualitativa, selecionamos oito pesquisas (três artigos científicos, três monografias e duas dissertações de mestrado).

Desta forma, a partir do material encontrado, demos início às leituras aprofundadas, com vistas à obtenção das respostas às perguntas de pesquisa.

\section{ANÁLISES E DISCUSSÕES: O QUE DIZEM OS PROFESSORES?}

Para iniciarmos as nossas análises, partimos das discussões sobre a ocorrência, ou não, do uso de tecnologias digitais em sala de aula pelos professores. Como houve, de fato, uma incidência relevante acerca da utilização de tais recursos, dedicamo-nos às análises sobre questões relacionadas ao incentivo institucional, assim como sobre opiniões e percepções dos docentes no que diz respeito ao uso dessas tecnologias no processo de ensino-aprendizagem.

\subsection{A utilização de tecnologias digitais em sala de aula}

Torna-se relevante mencionar que em todas as pesquisas que serviram como base para a análise qualitativa deste trabalho, encontramos vozes (percepções e opiniões) de professores, da rede pública e particular, atuantes no ensino fundamental, médio ou superior, que se manifestam positivamente quanto ao uso das tecnologias em 
sala de aula. (MIRANDA e ROCHA, 2020; FRANÇA, 2019; FASSINI, 2018; CAMPOS, 2018; ROCHA, 2018; PINHEIRO, 2017; PEREIRA, 2016; CENSI, 2017). Alguns docentes afirmam utilizarem essas tecnologias não somente durante as aulas, mas também para a comunicação com os alunos e orientação fora do ambiente escolar. Nesse sentido, podemos perceber como as tecnologias fazem parte do contexto de muitos professores e como esses profissionais consideram que esses recursos são relevantes para o processo de ensino-aprendizagem.

Fassini (2018), em sua pesquisa, questionou quinze professores de diferentes disciplinas de uma escola pública na intenção de verificar quais tecnologias eles utilizam em sala de aula. Assim, identificou-se que, embora os professores conheçam diferentes formas de tecnologias, as mais utilizadas por eles são o Datashow, o notebook, os jornais e os smartphones. Além do mais, a maioria dos professores pesquisados utiliza especificamente o smartphone como tecnologia para o ensino.

Resultados similares podem ser encontrados na pesquisa de Rocha (2018), feita com professores de inglês como língua estrangeira de uma escola pública. Quando foram perguntados sobre as tecnologias utilizadas em sala de aula, os professores anunciaram que atuam com o Datashow, o notebook e o dicionário digital visualizado pelo celular.

Já na pesquisa de França (2019), realizada com nove professores do ensino médio de uma, identificamos um significativo interesse quanto ao uso do smartphone, principalmente, pelo fato dessa tecnologia ser a que está mais presente nas mãos de docentes e alunos atualmente. Como complementação, o aplicativo WhatsApp também se torna uma ferramenta pedagógica, uma vez que os professores pesquisados se expressaram positivamente sobre o uso desse aplicativo para a realização de atividades tanto dentro como fora de sala de aula: criação de grupos para sanar dúvidas e trocar informações, orientação de trabalhos, informação sobre provas, etc.

À luz das informações apresentadas acima, notamos que as tecnologias mais atuais fazem parte do dia-a-dia dos professores. Contudo, em pesquisas como as de Miranda e Rocha (2020), Rocha (2018), e Pereira (2016), identificamos como o uso não apropriado dessas ferramentas pode não contribuir satisfatoriamente para o processo de ensino-aprendizagem. Mesmo que ocorra o uso das tecnologias em sala de aula, Rocha (2018) acredita que essa utilização é meramente substitutiva, ou seja, os professores 
pesquisados não têm o real conhecimento de como trabalhar com essas tecnologias efetivamente.

\subsection{O incentivo institucional ao uso dos smartphones em sala de aula}

Sabe-se que as restrições quanto à utilização de dispositivos móveis em ambientes educacionais ainda são muitas. A gestão escolar precisa lidar com fatores legislativos, dificuldades estruturais e resistência de parte do corpo docente, que alega inviabilidade no uso de celulares em sala de aula. No que diz respeito ao incentivo das instituições educacionais no que se refere ao uso de celulares nas escolas para fins pedagógicos, são diversas as indagações.

França (2019) aponta que mais de 90\% dos alunos da escola selecionada levam os seus aparelhos celulares para a escola e que $100 \%$ dos professores fazem o mesmo. No levantamento em questão, percebe-se que a maioria dos depoimentos dos alunos acerca da finalidade do uso do celular em sala de aula, além do entretenimento, contempla algo pedagógico, como realizar pesquisas no Google sobre conteúdos lecionados, fazer cálculos e até mesmo utilizar dicionários digitais. Portanto, o estudo indica que, se o uso do smartphone fosse direcionado didaticamente pelo professor, ele poderia ser uma ferramenta de utilidade pedagógica e não mais algo que poderia dispersar o foco dos educandos.

Tais resultados indicam que o smartphone está muito presente nesse cotidiano escolar. São, possivelmente, resultados que refletem a realidade de muitas escolas brasileiras, o que nos leva a discutir mais a fundo esta temática, com o intuito de obterse eventuais estratégias de aprendizagem através do seu uso. Sendo assim, levando em consideração as dificuldades a serem enfrentadas pelas gestões escolares, Gouvêa e Pereira (2015, apud FRANÇA, 2019) relatam que,

\footnotetext{
Acredita-se que esses sejam alguns dos grandes desafios para a atualidade e às ações futuras. Afinal, em pleno século XXI, ainda é possível encontrar grandes escolas que pró́bem os alunos quanto ao uso do celular. Em controvérsia, temos os jovens que já não conseguem viver sem seu smartphone e vivem sempre em busca de informações, se conectam com o mundo através do celular. Então se faz necessário e urgente a busca por propostas pedagógicas que possam usar o celular como ferramenta de aprendizagem na sala de aula. (GOUVÊA e PEREIRA, 2015, p.46 apud FRANÇA, 2019)
} 
Ainda sobre a análise do trabalho de França (2019), há dados que retratam a falta de incentivo das escolas quanto ao uso dos dispositivos móveis em relação ao corpo docente. Este é um indício de que muitos professores ainda enfrentam muita dificuldade em incentivar e mediar o uso do celular em sala de aula (ALVES E VIEIRA, 2015, p. 3). Nota-se também nesta realidade, segundo a S, que o professor ainda não domina estratégias que incorporem essa tecnologia de maneira satisfatória no dia a dia da sala de aula. Sob este viés, Alves e Vieira afirmam que:

\begin{abstract}
A sociedade está cada vez mais tecnológica e a escola mais do que nunca precisa se adequar, pois giz, quadro e livros não são mais atrativos suficientes para uma demanda jovem, cada vez mais "antenada", imersa no mundo virtual. Não adianta proibir o uso do celular, principalmente em sala de aula, é preciso buscar mecanismos que aproveitem seus recursos em favor da educação. Uma educação "conectada" poderá apresentar menores índices de evasão, menos casos de indisciplina e maior aproveitamento, visto que a aprendizagem poderá se tornar mais atraente tanto para quem ensina como para quem aprende [...] (ALVES e VIEIRA, 2015, p. 4)
\end{abstract}

Sendo assim, independente das determinações legais e normas escolares, a realidade escolar atual indica que as tecnologias móveis estão cada vez mais sendo introduzidas no ambiente escolar e acabam por gerar impasses, quanto ao seu uso, contribuições e consequências positivas e/ou negativas, conforme apontam Silva et al. (2019).

Ainda de acordo com os autores, para que se possa estabelecer um trabalho produtivo com o uso do celular em sala de aula, a gestão escolar deve desenvolver uma política instrucional que assegure o direito de professores e alunos a fazer o uso adequado dessa prática de forma indiscriminada. No entanto, tal gestão também deve garantir a execução dessa prática de maneira viável, garantindo a manutenção do acesso à internet, seus níveis de qualidade e monitoramento. Tais medidas precisam ser adotadas, segundo os especialistas, devido ao fato de que as salas de aula apresentam-se prostradas diante do universo interativo do aluno ao se deparar com um ambiente fechado, envolvido em práticas demasiadamente tradicionalistas. E a escola não conseguiu acompanhar o avanço tecnológico de forma a agregar as vantagens que tal recurso pode gerar (SILVA et al., 2019). 
Em suma, com base nas reflexões supracitadas, ainda há, irrefutavelmente, inúmeros aspectos a serem debatidos acerca da implementação do dispositivo móvel no âmbito educacional, no que se refere a um planejamento adequado por parte das instituições escolares.

\subsection{As vantagens e os entraves relacionados ao uso dos smartphones em sala de aula}

Com relação a visão dos docentes sobre vantagens e entraves no uso dos smartphones em sala de aula, os dados apresentados nas pesquisas selecionadas apontam para algumas questões relevantes.

Uma das vantagens, conforme levantado por Pinheiro (2017), é o aproveitamento das funções desses aparelhos para o contexto educacional. Além desta, a pesquisa realizada pela autora menciona também a ampliação das oportunidades de ensino para além do ambiente escolar, bem como o aumento da motivação dos alunos para a aprendizagem.

Quanto aos entraves, na maioria das pesquisas selecionadas há menções ao receio de dispersão do aluno durante as atividades com o uso dos smartphones. A falta de conhecimento técnico dos docentes no tocante a possibilidades de uso dessa tecnologia para fins pedagógicos também é um ponto destacado em muitos dos artigos (PINHEIRO, 2017; FASSINI, 2018; CAMPOS, 2018; FRANÇA, 2019; MIRANDA; ROCHA, 2020).

Além destes já mencionados, Campos (2018) traz ainda um dado relevante que surge em sua pesquisa: o medo de reprovação pelos pares e pelos familiares dos alunos. É interessante observar que esse medo pode estar relacionado ao caráter tradicionalista da educação, ainda enraizado em muitas escolas. O receio, na verdade, não está ligado apenas ao desafio imposto pelo novo, pelo uso das novas tecnologias, mas sim, ao quão negativamente esse uso pode ser interpretado pelos demais professores da escola e pelas famílias dos educandos. Paiva (2015, p. 21) afirma que "o sistema educacional sempre se viu pressionado pela tecnologia, do livro ao computador, e faz parte de sua história um movimento recorrente de rejeição, inserção e normalização". Esse dado, portanto, demonstra o quanto a inserção dos dispositivos móveis na educação parece ainda estar em um estágio de rejeição em algumas comunidades escolares. 
É interessante notar que em todas as pesquisas surge a questão da necessidade da formação docente para o uso dos smartphones em sala de aula, tanto nas respostas favoráveis ao uso, como naquelas contrárias. Sobre essa questão, Miranda e Rocha (2020, p. 114) afirmam que "mostra-se essencial que o professor, além de conscientizado sobre as possibilidades de uso, seja também treinado para conseguir manter o foco dos alunos e atuar como verdadeiro guia no ciberespaço". Na mesma linha de pensamento, França (2019, p. 26) destaca: “a formação do educador para o uso das tecnologias é essencial para a incorporação do celular no âmbito escolar e aproveitamento de suas funcionalidades".

Conseguimos perceber esse cenário apresentado também nas pesquisas de Silva et al. (2019), Fassini (2018), Campos (2018) e Pereira (2016). Em todos esses trabalhos, verificamos vozes que argumentam sempre em prol da necessidade de os professores estarem preparados e qualificados para o uso de tecnologias atuais, principalmente o celular, para o processo efetivo de ensino-aprendizagem. Silva et al. (2019) apontam para a necessidade da qualificação dos profissionais envolvidos, em uma formação de caráter informativo e conscientizador, propondo novas perspectivas para o trabalho docente em conformidade com as expressões da atualidade. Pereira (2016) argumenta ainda que é papel do governo investir na formação continuada de professores para a utilização do que chama de tecnologias não tradicionais em sala de aula.

\section{CONSIDERAÇÕES FINAIS}

Com base nos argumentos apresentados, entendemos que a aprendizagem móvel é um assunto que merece ser discutido, refletido e pesquisado na atualidade. Ainda que órgãos como a UNESCO defendam a utilização dos smartphones para fins pedagógicos em sala de aula e que a grande maioria dos alunos e professores utilize esses dispositivos em seus cotidianos, mudanças efetivas na cultura escolar para a incorporação dessa tecnologia em sua rotina não são instantâneas.

Nesse sentido, como professores atuantes de inglês, entendemos que os smartphones podem ser utilizados como recurso pedagógico tanto em escolas públicas como nas particulares e que essa utilização contribui satisfatoriamente para o processo de ensino-aprendizagem, especificando, neste artigo, da língua inglesa. Contudo, 
considerando que vivemos em uma sociedade em que os smartphones estão fortemente presentes, mudanças significativas precisam ser feitas para que a realidade do ensino de línguas estrangeiras seja favorecida por essas tecnologias.

Essas mudanças precisam ser feitas pelos três principais atores educacionais. O primeiro é a escola que deve investir em novas tecnologias e permitir que essas ferramentas façam parte do contexto educacional. O segundo é o próprio professor que precisa utilizar essas tecnologias em sala de aula para favorecer o aprendizado do inglês (e demais disciplinas) para os alunos. O último ator representa o aluno que precisa entender os benefícios das novas tecnologias para um efetivo processo de aprendizagem.

Em vista das diferentes realidades socioeconômicas das escolas de um país de dimensões continentais como o Brasil, não é difícil entender que essas mudanças não ocorrerão ao mesmo tempo, em todos os lugares, da mesma forma. Apropriando-nos dos conceitos de Paiva (2015), podemos afirmar que temos, no Brasil, diferentes estágios de aceitação do emprego das tecnologias e, portanto, dos smartphones no contexto educacional - rejeição, inserção e normalização.

De qualquer modo, entendemos que é preciso levar informação aos docentes, dar-lhes ferramentas para que eles mesmos possam tomar medidas de maneira consciente sobre suas práticas pedagógicas. A partir de nossos estudos, percebemos que, ainda que haja o interesse no trabalho com smartphones em sala de aula por parte de muitos docentes, a questão da formação e da conscientização para os benefícios da aprendizagem móvel ainda parece ser uma questão de suma importância. Nos contextos pesquisados, esta parece ser uma questão central para debate, não somente entre os docentes como para toda comunidade escolar.

\section{Referências}

ALVES, E. D. G.; VIEIRA, M. de F. Celular e sala de aula: dos limites às possibilidades. In: ANAIS DO XXI WORKSHOP DE INFORMÁTICA NA ESCOLA, 2015: Universidade Federal de Ouro Preto, 2015. Disponível em:https://www.academia.edu/33648566/Celular_e_sala_de_aula_dos_limites_\%C3\% A0s_possibilidades. Acesso em: 05 out. 2020.

BRASIL é $5^{\circ}$ país em ranking de uso diário de celulares no mundo. Empresa Brasil de 
Comunicação. Brasília, 18 de jan. de 2019. Disponível em:

https://agenciabrasil.ebc.com.br/geral/noticia/2019-01/brasil-foi-5o-pais-em-ranking-deuso-diario-de-celulares-no-mundo. Acesso em: 05 out. 2020.

BRASIL tem 230 milhões de smartphones em uso. Época Negócios. São Paulo, 29 de abr. de 2019. Disponível em:

https://epocanegocios.globo.com/Tecnologia/noticia/2019/04/brasil-tem-230-milhoesde-smartphones-em-uso.html. Acesso em 07 jan. 2020.

BRASIL. PCN+ Ensino Médio: orientações educacionais complementares aos Parâmetros Curriculares Nacionais: Linguagem, Códigos e suas tecnologias. Brasília: MEC, 2002.

CAMPOS, J. H. de S. Smartphones em sala de aula: possibilidades de uso como ferramenta didática. Porto Alegre, 2018. 53 p. Monografia (Especialização em mídias na educação) - Centro Interdisciplinar de Novas Tecnologias na Educação, Universidade Federal do Rio Grande do Sul.

CENSI, L. de J. L. Celulares na escola: implicações para práticas docentes. Linguagem, ensino e educação - Lendu, v. 1, n. 1, 2017. Disponível em:

http://periodicos.unesc.net/lendu/article/view/3202. Acesso em: 26 set. 2020.

CHEN, C. M. \& S.-H. HSU. (2008). Personalized Intelligent Mobile Learning System for Supporting Effective English Learnin. Educational Technology \& Society, v. 11, n. 3, p. 153-180. 2008. Disponível em: https://www.j-ets.net/collection/publishedissues/11_3. Acesso em: 25 set. 2020.

FASSINI, J. M. de A. O uso do dispositivo móvel como ferramenta avançada para a prática pedagógica em sala de aula. Porto Alegre, 2018. 26 p. Monografia (Especialização em mídias na educação) - Centro Interdisciplinar de Novas Tecnologias na Educação, Universidade Federal do Rio Grande do Sul.

FONSECA, A. G. M. F. (2013). Aprendizagem, Mobilidade e Convergência: Mobile learning com Celulares e Smartphone. Revista Eletrônica do programa de PósGraduação em Mídia e Cotidiano, n 2, p. 265-283. 2013. Disponível em: https://periodicos.uff.br/midiaecotidiano/article/view/9685. Acesso em: 25 set. 2020.

FRANÇA, E. de F. M. O uso do celular (smartphone) como instrumento de aprendizagem nas aulas do ensino médio. Sabará, 2019. Monografia (Especialização em mídias na educação) - Núcleo de Educação à Distância, Universidade Federal de São João Del Rei.

IBGE EDUCA. Uso de internet, televisão e celular no Brasil. Disponível em: https://educa.ibge.gov.br/jovens/materias-especiais/20787-uso-de-internet-televisao-ecelular-no-brasil.html\#subtitulo-1. Acesso em: 25 set. 2020.

LIMA, M. C. Monografia: a engenharia da produção acadêmica. São Paulo: Saraiva, 2004. 
MARCONI, M. de A.; LAKATOS, E. M. Técnicas de pesquisa: planejamento e execução de pesquisas, amostragens e técnicas de pesquisa, elaboração, análise e interpretação de dados. 4. ed. São Paulo: Atlas, 1999.

MELO, R. S.; NEVES, B. G.B. (2014). Aplicativos Educacionais Livres para Mobile Learning. Revista Tecnologias na Educação. Ano 6 - Número/vol.10. Disponível em: http://tecnologiasnaeducacao.pro.br/wp-content/uploads/2015/07/Art3-ano6-vol10 julho2014.pdf. Acesso em: 25 set. 2020.

MIANGAH, T. M., \& NEZARAT, A. (2012). Mobile-Assisted Language Learning. International Journal of Distributed and Parallel Systems, v. 3, n. 1, p. 309-319, 2012. Disponível em: http://airccse.org/journal/ijdps/papers/0112ijdps26.pdf. Acesso em: 25 set. 2020.

MILRAD, M. 2007. "How should learning activities using mobile technologies be designed to support innovative educational practices?". In: Big issues in mobile learning: Report of a workshop by the Kaleidoscope Network of Excellence Mobile Learning Initiative, ed. M. Sharples, 29-31. Nottingham: Learning Science Research Institute, University of Nottingham.

MIRANDA, J. F. B.; ROCHA, J. D. T. Cibercultura e mobilidade: a utilização de smartphones em sala de aula. Humanidades \& Inovação, Palmas, v. 7, n. 9, p. 104 120, mar. 2020. Disponível em:

https://revista.unitins.br/index.php/humanidadeseinovacao/article/view/1933. Acesso em: 26 set. 2020 .

PAIVA, V. L. M. De O. O uso da tecnologia no ensino de línguas estrangeiras: breve retrospectiva histórica. In: JESUS, D. M. de; MACIEL, R. F. (Orgs.) Olhares sobre tecnologias digitais: linguagens, ensino, formação e prática docente. Coleção: Novas Perspectivas em Linguística Aplicada, v. 44. Campinas: Pontes Editores, 2015, p. 21 34.

PEREIRA, J. da S. Do consumo as apropriações: o uso de smartphones por estudantes do ensino médio em Cuiabá. Anagrama, v. 10, n. 1, p. 1 - 19, jan./jun, 2016. Disponível em: http://www.revistas.usp.br/anagrama/article/view/108978. Acesso em: 26 set. 2020. PINHEIRO, I. Q. Explorando as affordances do uso de dispositivos móveis na formação continuada de professores de língua inglesa. Belo Horizonte, 2017. $111 \mathrm{p}$. Dissertação (Mestrado em linguística aplicada) - Faculdade de Letras, Universidade Federal de Minas Gerais.

RIO DE JANEIRO. Lei $n^{\circ}$ 4734, de 04 de janeiro 2008. Proíbe a utilização de telefone celular e outros em sala de aula. Leis Municipais. Disponível em: htt p://www.leismunicipais.com.br. Acesso em: 01 out. 2020.

ROCHA, F. R. da. Uso das tecnologias digitais de informação e comunicação aplicadas ao ensino de língua inglesa: um estudo de caso em uma escola da rede 
pública de ensino de Tefé - Amazonas. Braga, 2018. 96 p. Dissertação (Mestrado em ciências da educação) - Instituto de Educação, Universidade do Minho.

SANTAELLA, L. Desafios da ubiquidade para a educação. 2013. Disponível em: https://www.revistaensinosuperior.gr.unicamp.br/edicoes/edicoes/ed09_abril2013/NME S_1.pdf. Acesso em: 05 out. 2020.

SILVA, R. J. de M.; SANTOS, L. dos. A.; LIMA, I. L. C.; GUIMARÃES, R. M. G.de S.; MEDEIROS, F. M. S. de.; QUEIROZ, J. F. de. O uso de smartphones em sala de aula: entre dificuldades e possibilidades no trabalho docente. Revista Científica Semana Acadêmica. Fortaleza, ano MMXIX, No . 000170, 2019. Disponível em:https://semanaacademica.com.br/artigo/o-uso-de-smartphones-em-sala-de-aulaentre-dificuldades-e-possibilidades-no-trabalho-docente Acessado em: 01 de out. 2020.

SONEGO, A. H. S; BEHAR, P. A. M-Learning: Reflexões e perspectivas com o uso de aplicativos educacionais. In: XX Congresso Internacional de Informática Educativa (TISE), 2015, Santiago. NuevasIdeasen Informática Educativa TISE 2015. Santiago, 2015. v.11. p.521-526.

UNESCO. Diretrizes de políticas para a aprendizagem móvel. 2014. Disponível em: <http://unesdoc.unesco.org/images/0022/002277/227770por.pdf>. Acesso em: 17 ago. 2018.

Recebido em: 25/01/2021

Aceito em: 26/02/2021

\footnotetext{
${ }^{1}[\ldots]$ the emerging of internet made open and distance learning a means of receiving education from all parts of the world. In a short period, the attractiveness of distance learning led to the realization that various mobile devices provide a very effective resource for education. This way, many researchers tried to make mobile devices a rich resource for teaching and learning. It was, in fact, a challenging affair to cover learning tasks by a mobile phone.

${ }^{2}$ https://scholar.google.com.br/?hl=pt
} 